\title{
Research
}

\section{Ethnic differences in primary care management of diabetes and cardiovascular disease in people with serious mental illness}

\begin{abstract}
Background

Patients with serious mental illness (SMI) have high rates of cardiovascular disease (CVD). In contrast to widespread perception, their access to effective chronic disease management is as high as for the general population. However, previous studies have not included analysis by ethnicity.
\end{abstract}

\section{Aim}

To identify differences in CVD and diabetes management, by ethnicity, among people with SMI.

\section{Design and setting}

Three inner east London primary care trusts with an ethnically diverse and socially deprived population. Data were obtained from 147 of 151 general practices.

\section{Method}

Coded demographic and clinical data were obtained from GP electronic health records using EMIS Web. The sample used was the GP registered population on diabetes or CVD registers (52 620); of these, 1223 also had SMI.

\section{Results}

The population prevalence of CVD and diabetes is $7.2 \%$; this rises to $18 \%$ among those with SMI. People with SMI and CVD or diabetes were found to be as likely to achieve clinical targets as those without SMI. Blood pressure control was significantly better in people with SMI; however, they were more likely to smoke and have a body mass index above $30 \mathrm{~kg} / \mathrm{m}^{2}$. Ethnic differences in care were identified, with south Asian individuals achieving better cholesterol control and black African or Caribbean groups achieving poorer blood pressure control

\section{Conclusion}

Risk factor management for those with SM shows better control of blood pressure and glycosylated haemoglobin than the general population. However, smoking and obesity rates remain high and should be the target of public health programmes. Ethnic differences in management mirror those in the general population. Ethnic monitoring for vulnerable groups provides evidence to support schemes to reduce health inequalities.

\section{Keywords}

cardiovascular diseases; diabetes mellitus ethnicity; health; inequalities; mental disorders primary care.

\section{INTRODUCTION}

Patients with serious mental illness (SMI), including schizophrenia, bipolar affective disorder, and other psychoses, have lower life expectancy and higher rates of cardiovascular disease (CVD) than those without these conditions.1-4 Smoking, obesity, and diabetes are 2-3 times as likely among people with $\mathrm{SMI}$ as in those without SMI. ${ }^{5}$ Among those with SMI and diabetes, mortality is increased in comparison to those without SMI. ${ }^{6}$ Antipsychotic medication is associated with diabetes but the impact on CVD and total mortality is unclear. ${ }^{7,8}$

Earlier reviews have found evidence that people with SMI may not access health services for routine physical care and effective management of CVD risk factors. However, more recent studies suggest that care provision and adherence to treatment of diabetes and CVD risk factors in people with $\mathrm{SMI}$ is as good as, if not better than, that of the population without SMI. ${ }^{10}$ In the UK, studies among those with CVD and schizophrenia have found no significant differences in indicators of care or prescribing, apart from less statin prescribing for those with schizophrenia and diabetes. ${ }^{10}$ Similar findings have been reported from integrated care in both Canada and the US. ${ }^{11,12}$ Continuity of primary care is associated with treatment retention and survival benefit. ${ }^{13}$

Psychoses are more common among

R Mathur, BSc, MSc, research fellow; SA Hull MSc, FRCGP, MRCP, reader in primary care; K Boomla, MSc, FRCGP MRCP, senior lecturer; J Robson, FRCGP, MD, reader in primary care, Blizard Institute, Queen Mary University of London London.

\section{Address for correspondence}

Rohini Mathur, Centre for Primary Care and Public Health, Barts and the London School of Medicine and Dentistry, Queen Mary, University of London, Yvonne Carter Building, 58 Turner Street, black African or Caribbean groups, ${ }^{14,15}$ and the accumulation of cardiovascular risk factors in these groups is associated with additional comorbidities and mortality. Few studies have considered the joint contributions of ethnicity and deprivation to measures of care provision. This study considers chronic disease management for people with diabetes and CVD who also have SMI, by ethnic group.

\section{METHOD}

The study was based in 147 of the 151 general practices in Tower Hamlets, City and Hackney, and Newham Primary Care Trusts in east London, which serve $98 \%$ of the population of 850000 people. These practices use the same web-enabled computer system for their electronic medical records, and use prespecified codes for recording data on chronic disease management. Anonymised patient data were accessed via EMIS Web (http://www.emis-online.com/emis-web) in June 2011. The study sample included all adult patients laged >18years) with diagnostic Read Codes for diabetes (type 1 or type 2) or cardiovascular disease lany one of ischaemic heart disease, stroke, or transient ischaemic attack [TIA]).

The most recent recordings, within the previous 15 months, of systolic and diastolic blood pressure, total cholesterol, body mass index (BMI), glycosylated haemoglobin (HbA1c) level, and smoking status were

Whitechapel, London, E1 2AB.

E-mail: r.mathurdamul.ac.uk

Submitted: 22 December 2011; Editor's response 29 February 2012; final acceptance: 22 March 2012

CBritish Journal of General Practice

This is the full-length article (published online 30 Jul 2012) of an abridged version published in print. Cite this article as: Br J Gen Pract 2012; DOI: 10.3399/bjgp12X653642 


\section{How this fits in}

This article confirms a high prevalence of diabetes and cardiovascular disease among patients with severe mental illness. In contrast to common perception, management of most cardiovascular disease (CVD) risk factors is as good, or better, than for the general population. Ethnic differences in CVD management mirror those in the general population.

used for analysis. Retinopathy screening and the issue of a prescription for lipidlowering or antihypertensive medication were also included if recorded in the previous 15 months. Clinical targets for risk factors were based on the National Institute for Health and Clinical Excellence (NICE) guidelines. The targets for each of the risk factors were as follows: systolic blood pressure $<140 \mathrm{mmHg}$, total cholesterol level $<4 \mathrm{mmol} / \mathrm{l}$, and $\mathrm{HbA} 1 \mathrm{c}<7.5 \%$.

Attainment of clinical targets was determined by constructing categorical variables that equalled 0 if the target was not met and 1 if it was. For BMI, a differential definition of obesity based on ethnic group was utilised. Prior research has shown that a BMI threshold of $30 \mathrm{~kg} / \mathrm{m}^{2}$ does not adequately describe adiposity in south Asian people, which occurs at a BMI of $24-25 \mathrm{~kg} / \mathrm{m}^{2}$ instead of $30 \mathrm{~kg} / \mathrm{m}^{2}$ in white individuals. ${ }^{16-18}$ For south Asian patients, the cut-off for being obese was set at a BMI of over $25 \mathrm{~kg} / \mathrm{m}^{2}$. For patients who were not south Asian, the cut-off was set at a BMI of $>30 \mathrm{~kg} / \mathrm{m}^{2}$.

aged 18 years and above. $C V D=$ cardiovascular disease. SMI = serious mental illness.

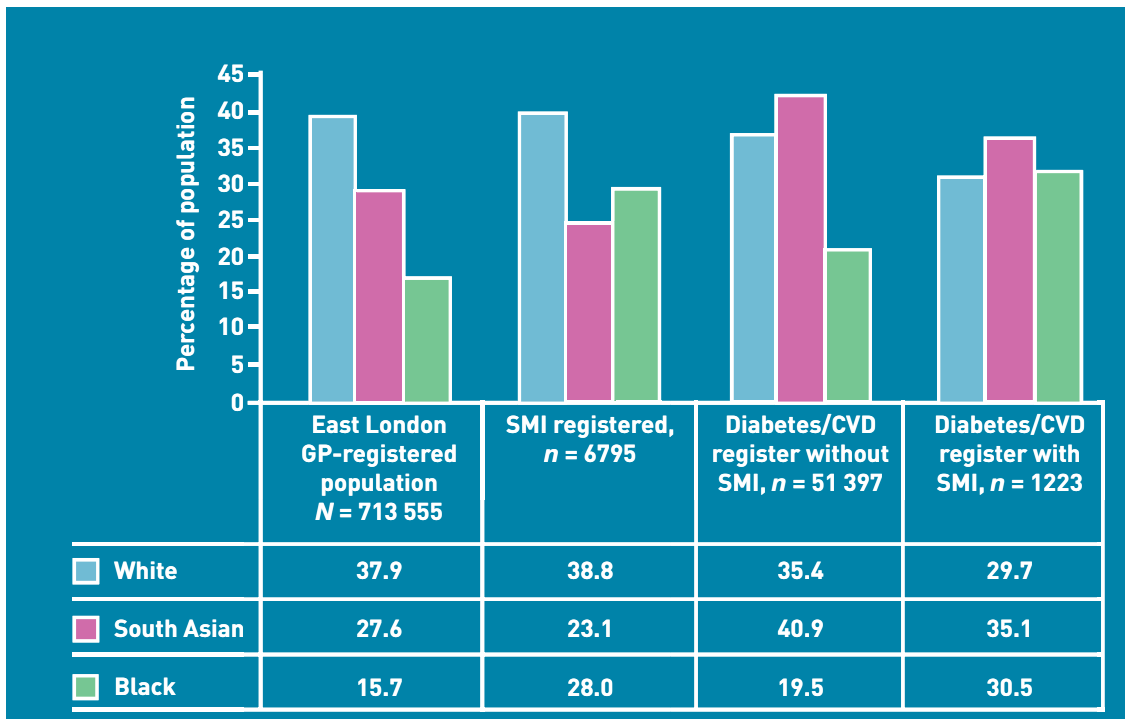

East London GP-registered population as of 1 April 2011; SMI register as of 1 April 2010
Ethnicity was self-reported by patients and recorded using the $16+1$ ethnicity groupings defined in the 2001 census. For this study, the ethnic groups were collapsed into four categories; white (British, Irish, other white); south Asian (Bangladeshi, Indian, Pakistani, other Asian, mixed Asian); black (African, Caribbean, black British, mixed black); and other (any other recorded ethnic group). Patients whose ethnicity could not be classified from the recorded entry due to non-response or coding error were excluded from the analysis. Patients who identified themselves as mixed origin were grouped with their parent ethnic minority, as this was felt to be more biologically relevant than creating a distinct 'mixed ethnic group' category.

This patient sample was then further divided into two groups based on the presence or absence of SMI. This definition was based on the Quality and Outcomes Framework for general practice, but excluded those patients with major depressive disorders and personality disorders (see Appendix 1 for diagnostic codes included).

\section{Statistical analyses}

STATA (version 10) was used for both the adjusted and unadjusted univariable and multivariable analyses. First, the crude odds of being on the SMI register were examined by age, sex, and ethnic group. Next, the proportion of patients with and without SMI meeting clinical targets was investigated using logistic regression. Finally, the achievement of clinical targets was investigated by ethnicity among the group with both SMI and diabetes or CVD. All logistic regression analyses were adjusted for age, sex, social deprivation, and ethnic group and clustered by practice to account for intra-practice correlation and shared patient characteristics.

\section{RESULTS}

Of the total adult ( $>18$ years) east London GP-registered population of $713555,38 \%$ were white, $28 \%$ were south Asian and $16 \%$ were black. Based on the Townsend score, $81 \%$ of patients fell into the most socially deprived quintile. Valid self-reported ethnicity was recorded for $87.1 \%$ of the entire east London population and $96.8 \%$ of the study sample. The combined diabetes and CVD register across inner east London consisted of 52620 patients aged $>18$ years; $76.4 \%$ had either type 1 or type 2 diabetes, $12.6 \%$ had stroke/TIA, and $37.7 \%$ had CVD. Within this population, 1223 patients $(2.3 \%$ of the registers) also had a diagnosis of SMI. 
Table 1. Crude odds for people with diabetes or cardiovascular disease being on a serious mental illness register by age, sex and ethnic group

\begin{tabular}{lccc} 
Demographic & Crude odds ratio & $\mathbf{9 5 \%} \mathbf{C l}$ & $P$-value \\
\hline $\begin{array}{l}\text { Age, years } \\
<60 \text { (reference) }\end{array}$ & 1 & & \\
$>60$ & 0.62 & 0.55 to 0.70 & $<0.001$ \\
\hline $\begin{array}{l}\text { Sex } \\
\text { Male (reference) }\end{array}$ & 1 & & \\
Female & 1.24 & 1.11 to 1.39 & $<0.001$ \\
\hline $\begin{array}{l}\text { Ethnic group } \\
\text { White (reference) }\end{array}$ & 1 & & \\
South Asian & 0.99 & 0.86 to 1.14 & 0.921 \\
Black & 1.82 & 1.57 to 2.10 & $<0.001$ \\
Other & 1.03 & 0.76 to 1.41 & 0.839 \\
\hline
\end{tabular}

Table 2. Proportions of people on the diabetes and cardiovascular disease register with and without serious mental illness meeting clinical targets and odds ratios comparing the two groups

\begin{tabular}{|c|c|c|c|c|}
\hline Process of care variable & $\begin{array}{l}\text { No SMI, } n(\%) \\
(\mathrm{N}=51397)\end{array}$ & $\begin{array}{l}\text { SMI, } n(\%) \\
(N=1223)\end{array}$ & $\begin{array}{l}\text { Adjusted } \\
\text { odds ratio }\end{array}$ & $95 \% \mathrm{Cl}$ \\
\hline \multicolumn{5}{|l|}{ Cholesterol control } \\
\hline Total cholesterol $<4 \mathrm{mmol} / \mathrm{l}$ & $24971(48.6)$ & 578 (47.3) & 1.11 & 0.98 to 1.26 \\
\hline Statin treatment & 43260 (84.2) & $998(81.6)$ & 1.12 & 0.95 to 1.31 \\
\hline \multicolumn{5}{|l|}{ Blood pressure control } \\
\hline $\mathrm{SBP}<140 \mathrm{mmHg}$ & 41196 (80.2) & 1040 (85.0) & 1.32 & 1.11 to 1.56 \\
\hline Antihypertensive treatment & 41897 (81.5) & $856(70.0)$ & 0.65 & 0.55 to 0.77 \\
\hline Current smoker & $8426(16.4)$ & $401(33.0)$ & 2.62 & 2.25 to 3.05 \\
\hline \multicolumn{5}{|c|}{ Glycaemic control/diabetes care } \\
\hline $\mathrm{HbA} 1 \mathrm{c}<7.5 \%{ }^{\mathrm{b}}$ & 15530 (39.7) & $499(47.0)$ & 1.43 & 1.27 to 1.60 \\
\hline Retinopathy screening ${ }^{b}$ & $33105(84.6)$ & 82878.0 & 0.70 & 0.58 to 0.85 \\
\hline Obesityc & 28256 (54.98) & 757 (61.9) & 1.29 & 1.11 to 1.49 \\
\hline \multicolumn{5}{|c|}{$\begin{array}{l}\text { HbAlc }=\text { glycosylated haemoglobin. SBP = systolic blood pressure. SMI = serious mental illness. }{ }^{a} \text { Odds ratios } \\
\text { adjusted by age, sex, ethnic group, and deprivation, and clustered by practice. }{ }^{b} \text { Among patients with diabetes } \\
\text { only }\left(\mathrm{n}=1061 \text { for patients with SMI). }{ }^{c} \text { Body mass index }(B M I)>30 \mathrm{~kg} / \mathrm{m}^{2} \text { for white and black individuals; BMI }\right. \\
>25 \mathrm{~kg} / \mathrm{m}^{2} \text { for south Asian individuals. }\end{array}$} \\
\hline
\end{tabular}

Table 3. Serious mental illness with diabetes or cardiovascular disease: adjusted odds ratios ${ }^{\mathrm{a}}$ for cholesterol control targets by ethnic group

\begin{tabular}{|c|c|c|c|c|}
\hline \multirow[b]{2}{*}{ Ethnic group } & \multicolumn{2}{|c|}{ Cholesterol $<4 \mathrm{mmol} / \mathrm{l}$} & \multicolumn{2}{|c|}{ Statin prescribed } \\
\hline & OR & $95 \% \mathrm{Cl}$ & OR & $95 \% \mathrm{Cl}$ \\
\hline White (reference) & 1 & & 1 & \\
\hline South Asian & 1.50 & 1.13 to 1.99 & 1.30 & 0.86 to 1.96 \\
\hline Black & 1.02 & 0.75 to 1.55 & 0.64 & 0.44 to 0.93 \\
\hline
\end{tabular}

$\mathrm{OR}=$ odds ratio. ${ }^{\mathrm{a}}$ Odds ratios adjusted by age, sex, ethnic group, and deprivation, and clustered by practice.

Table 4. Serious mental illness with diabetes or cardiovascular

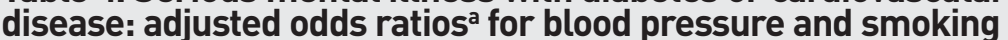
targets by ethnic group

\begin{tabular}{|c|c|c|c|c|c|c|}
\hline \multirow[b]{2}{*}{ Ethnic group } & \multicolumn{4}{|c|}{$\begin{array}{l}\text { On antihypertensive } \\
\text { medication }\end{array}$} & \multicolumn{2}{|c|}{ Current smoker } \\
\hline & $\overline{O R}$ & $95 \% \mathrm{Cl}$ & OR & $95 \% \mathrm{Cl}$ & OR & $95 \% \mathrm{Cl}$ \\
\hline White (reference) & 1 & & 1 & & 1 & \\
\hline South Asian & 0.99 & 0.62 to 1.58 & 0.95 & 0.66 to 1.35 & 0.27 & 0.19 to 0.37 \\
\hline Black & 0.70 & 0.47 to 1.05 & 0.97 & 0.69 to 1.37 & 0.53 & 0.38 to 0.73 \\
\hline
\end{tabular}

Figure 1 shows a breakdown of the east London population by disease register and ethnicity.

Differences between patients with and without SMI

Among the adult population of east London, the combined prevalence of diabetes and CVD was $7.2 \%$; this rose to $18 \%$ among the population with SMI. In the study sample of 52260 patients with diabetes or CVD, the crude percentages show that the proportion of black African or Caribbean patients is higher among patients with SMI than those without $(30.5 \%$ versus $19.5 \%)$. This is supported by odds ratios that indicate that patients from black African or Caribbean groups are significantly more likely to be on SMI registers than white patients. The odds of having both diabetes or CVD and SMI are significantly reduced in older people compared to younger individuals, but increased by $24 \%$ for females compared to males (Table 1).

\section{Comparison of people with}

diabetes/cardiovascular disease with and without serious mental illness

Differences in care between those with and without a diagnosis of SMI were examined first. Table 2 shows the number and proportion of patients on the diabetes or CVD register with and without $\mathrm{SMI}$ achieving clinical targets. Odds ratios (ORs) demonstrate no significant differences in cholesterol control or statin prescribing between those with or without SMI. Blood pressure control was significantly better among patients with SMI, even though less antihypertensive medication was prescribed. Patients with SMI were more likely to be current smokers and more likely to be obese. Patients with SMI and diabetes were more likely to have their $\mathrm{HbA} 1 \mathrm{c}$ controlled to $<7.5 \%$ but less likely to have had retinopathy screening completed.

Ethnicity, serious mental illness and diabetes or cardiovascular disease Among patients with SMI and diabetes or CVD, Table 3 shows that south Asian patients were significantly more likely to be prescribed statins $(\mathrm{OR}=1.3)$ and achieve cholesterol targets $(O R=1.58)$. Both south Asian and black African or Caribbean patients were significantly less likely to be current smokers compared to white patients $(\mathrm{OR}=0.27$ and 0.53 respectively) (Table 4). Black African or Caribbean patients were significantly less likely to be prescribed statins $(\mathrm{OR}=0.64)$ and had worse blood pressure control, but 


\section{Table 5. Serious mental illness with diabetes or cardiovascular disease: adjusted odds ratios ${ }^{\mathrm{a}}$ for glycaemic control and diabetes care targets by ethnic group}

\begin{tabular}{|c|c|c|c|c|c|c|}
\hline \multirow[b]{2}{*}{ Ethnic group } & \multicolumn{2}{|c|}{ HbA1c $<7.5 \%$ b } & \multicolumn{2}{|c|}{$\begin{array}{c}\text { Retinopathy } \\
\text { screening done }^{\text {b }}\end{array}$} & \multicolumn{2}{|c|}{ Obesityc } \\
\hline & OR & $95 \% \mathrm{Cl}$ & OR & $95 \% \mathrm{Cl}$ & OR & $95 \% \mathrm{Cl}$ \\
\hline White (reference) & 1 & & 1 & & 1 & \\
\hline South Asian & 0.86 & 0.60 to 1.24 & 1.26 & 0.91 to 1.74 & 1.89 & 1.37 to 2.63 \\
\hline Black & 0.92 & 0.64 to 1.33 & 1.29 & 0.93 to 1.78 & 0.83 & 0.58 to 1.18 \\
\hline
\end{tabular}

antihypertensive medication did not differ between ethnic groups (Table 4).

All ethnic groups with diabetes and SMI had similar proportions of individuals achieving the HbA1c target of $<7.5 \%$ (Table 5), but south Asian groups were more likely to exceed the threshold values for obesity (OR $=1.89)$

\section{DISCUSSION}

\section{Summary}

This study, located in an ethnically diverse and socially deprived part of the UK, confirms findings of earlier studies that demonstrate equality of chronic disease management in primary care settings for diabetes and CVD between those with and without SMI.

As shown in other parts of London, this study has found that patients of black African or Caribbean ethnicity are overrepresented on SMI registers, with $28 \%$ compared to $15.7 \%$ in the general adult population. ${ }^{19}$ It also confirms the high prevalence of diabetes and CVD in this group of patients : the prevalence of $18 \%$ is more than twice that of the general population.

Most process of care measures were similar in those with and without SMI although the study findings confirm that patients with SMI have higher rates of smoking and obesity. Unlike some UK studies that found reduced statin use, the present study found it was similar in those with and without SMI. This may reflect the high local rates of prescribing of these drugs, which have been over $90 \%$ in recent years for those with CVD. The unexpected finding of improved $\mathrm{HbA1c}$ control in people with diabetes and SMI has also been described in another UK study. ${ }^{20,21}$

This study is the first to describe improved blood pressure control in people with SMI. This may result from the hypotensive effect of concurrent medication for SMI, although the rate and intensity of prescribing of
Contribute and read comments about http://www.rcgp.org.uk/bjgp-discuss
In east London, the ethnic differences in cardiovascular management for patients with SMI follow those already described in the general population, with better statin uptake and cholesterol control in south Asian groups, and higher rates of smoking in white groups. The lower use of statins in black individuals has been described in the US, and is a persistent local finding. ${ }^{22}$ Using a threshold BMI value of $25 \mathrm{~kg} / \mathrm{m}^{2}$ as a marker of obesity in south Asian groups, this study found that south Asian patients with SMI have almost twice the odds of being obese as compared to white patients (OR $=1.89 ; 95 \%$ confidence interval $[\mathrm{Cl}]=1.37$ to 2.63 ).

\section{Strengths and limitations}

The high levels of self-reported ethnicity in this large study population enable accurate estimation of the prevalence of SMI, and the management of diabetes and CVD by ethnicity. Efforts to identify patients with $\mathrm{SMI}$, and incentives to promote physical health checks, have been supported by the Quality and Outcomes Framework for general practice since 2004; hence, it is likely that the vast majority of patients with SMI with chronic psychotic disorders registered with general practice have been included in this study.

Study limitations include a lack of rigour in the inclusion criteria for SMI, which includes chronic schizophrenia and bipolar affective disorders, alongside single episodes of psychosis: possibly drug induced. Patients with SMI who are highly mobile, and others not registered with a GP. may have more severe disease and worse cardiovascular outcomes. The reliance on clinical data entered during routine consultations may introduce data of varying quality and completeness.

\section{Comparison with existing literature}

These findings are reassuring, and refute the common perception that people with SMI have poor access and uptake of chronic disease management in primary care settings. This study indicates that those with both SMI and diabetes or CVD are treated in a similar fashion to those without SMI. These findings are supported by other recent studies. ${ }^{10}$

\section{Implications for practice}

The high rates of smoking in the population of white individuals with SMI would benefit from targeted public health interventions: the same is true for obesity, which is an increasing problem for all those with SMI, particularly south Asian groups. Access to retinopathy screening could be improved for antipsychotic drugs was not examined. 
all those with SMI. The persistent lower uptake of statins among black African or Caribbean people at high risk of CVD merits further investigation.

Studies such as this are only possible with high rates of ethnicity recording in the general practice record. In areas with large populations from black and minority ethnic groups, commissioning organisations should be encouraged to support practicelevel recording of ethnicity and language, to develop accurate estimates of disease prevalence and local population needs. This will provide a framework to support efforts to identify, challenge, and modify existing health inequalities in health service provision and utilisation. 


\section{REFERENCES}

1. Tiihonen J, Lonnqvist J, Wahlbeck K, et al. 11-year follow-up of mortality in patients with schizophrenia: a population-based cohort study (FIN11 study) Lancet 2009; 374(9690): 620-627.

2. Chang CK, Hayes RD, Perera G, et al. Life expectancy at birth for people with serious mental illness and other major disorders from a secondary mental health care case register in London. PLoS One 2011; 6(5): e19590.

3. Osborn DP, Levy G, Nazareth I, et al. Relative risk of cardiovascular and cancer mortality in people with severe mental illness from the United Kingdom's General Practice Rsearch Database. Arch Gen Psychiatry 2007; 64(2): 242-249

4. Thornicroft G. Physical health disparities and mental illness: the scandal of premature mortality. Br J Psychiatry 2011; 199(6): 441-442.

5. Brown C, Leith J, Dickerson F, et al. Predictors of mortality in patients with serious mental illness and co-occurring type 2 diabetes. Psychiatry Res 2010 177(1-2): 250-254

6. Vinogradova Y, Coupland C, Hippisley-Cox J, et al. Effects of severe mental illness on survival of people with diabetes. Br J Psychiatry 2010; 197(4): 272-277.

7. Brauer R, Douglas I, Smeeth PL. The association between antipsychotic agents and the risk of myocardial infarction - a systematic review. Br J Clin Pharmacol 2011; 72(6): 871-878.

8. Koro CE, Fedder DO, L'Italien GJ, et al. Assessment of independent effect of olanzapine and risperidone on risk of diabetes among patients with schizophrenia: population based nested case-control study. BMJ 2002; 325(7358): 243.

9. Phelan M, Stradins L, Morrison S. Physical health of people with severe mental illness. BMJ 2001; 322(7284): 443-444.

10. Hippisley-Cox J, Parker C, Coupland C, Vinogradova Y. Inequalities in the primary care of patients with coronary heart disease and serious mental health problems: a cross-sectional study. Heart 2007; 93(10): 1256-1262

11. Kreyenbuhl J, Leith J, Medoff DR, et al. A comparison of adherence to hypoglycemic medications between type 2 diabetes patients with and without serious mental illness. Psychiatry Res 2011; 188(1): 109-114.

12. Bresee LC, Majumdar SR, Patten SB, Johnson JA. Diabetes, cardiovascular disease, and health care use in people with and without schizophrenia. Eur Psychiatry 2010; 26(5): 327-332

13. Copeland LA, Zeber JE, Wang CP, et al. Patterns of primary care and mortality among patients with schizophrenia or diabetes: a cluster analysis approach to the retrospective study of healthcare utilization. BMC Health Serv Res 2009; 9 : 127.

14. Kirkbride JB, Barker D, Cowden F, et al. Psychoses, ethnicity and socioeconomic status. Br J Psychiatry 2008; 193(1): 18-24.

15. Fearon P, Kirkbride JB, Morgan C, et al. Incidence of schizophrenia and other psychoses in ethnic minority groups: results from the MRC AESOP Study. Psychol Med 2006; 36(11): 1541-1550.

16. Chiu M, Austin PC, Manuel DG, et al. Deriving ethnic-specific BMI cutoff points for assessing diabetes risk. Diabetes Care 2011; 34(8): 1741-1748.

17. Misra A, Khurana L. Obesity-related non-communicable diseases: South Asians vs White Caucasians. Int J Obes 2011; 35(2): 167-187.

18. Anand SS, Tarnopolsky MA, Rashid S, et al. Adipocyte hypertrophy, fatty liver and metabolic risk factors in South Asians: the Molecular Study of Health and Risk in Ethnic Groups (mol-SHARE). PLoS One 2011; 6(7): e22112.

19. Bhui K, Stansfeld S, Hull S, et al. Ethnic variations in pathways to and use of specialist mental health services in the UK. Systematic review. Br J Psychiatry 2003; 182: 105-116.

20. Hippisley-Cox J, O'Hanlon S, Coupland C. Association of deprivation, ethnicity, and sex with quality indicators for diabetes: population based survey of 53,000 patients in primary care. BMJ 2004; 329(7477): 1267-1269.

21. Whyte S, Penny C, Phelan M, et al. Quality of diabetes care in patients with schizophrenia and bipolar disorder: cross-sectional study. Diabet Med 2007; 24(12): 1442-1448

22. Mathur R, Hull SA, Badrick E, Robson J. Cardiovascular multimorbidity: the effect of ethnicity on prevalence and risk factor management. Br J Gen Pract 2011; 61(586): e262-270. 


\begin{tabular}{|c|c|}
\hline Variable & Read Code \\
\hline \multicolumn{2}{|c|}{ Demographic/diagnosis variables } \\
\hline Patient details & Anonymised ID, Age, Sex, Organisation Code, Townsend Score, PCT \\
\hline Ethnicity & $9 i \%, 95 \%$ \\
\hline IHD & G3... Ischaemic heart disease \\
\hline Stroke/TIA & $\begin{array}{l}\text { G61, G610, G611, G612, G613, G614, G615, G616, G618, G61X0, } \\
\text { G61X1, G61z, G63y0\%, G63y1\%, G64\%, G66\%, G6760\%, G6W\%, } \\
\text { G6X\%, G65-G654, G656-G65zz, F4236 }\end{array}$ \\
\hline Diabetes mellitus & C10\% Diabetes Mellitus \\
\hline Serious mental illness & $\begin{array}{l}\text { Eu20\%, E10\%, Eu31\%, E11z, E11z0, E11zz, E110\%, E111\%, } \\
\text { E114-E117z, E11y-E11y1, E11yz, Eu25\% }\end{array}$ \\
\hline \multicolumn{2}{|l|}{ Process of care variables } \\
\hline Total serum cholesterol & $44 \mathrm{P}$ \\
\hline Systolic blood presure & 2469. O/E - Systolic BP reading \\
\hline Diastolic blood pressure & 246A. O/E - Diastolic BP reading \\
\hline Smoking status & 137.. Tobacco consumption \\
\hline HbAlc level & 42W..\% lexcluding 42W5.), 42c..\%, 44TB., 44TC., 44TL. \\
\hline Retinopathy screening & 68A8, 9N2f, 9N1V \\
\hline Mental health screening & 6A6.. Mental health review \\
\hline BMI & $22 \mathrm{~K} .$. Excl $22 \mathrm{~K} 9$ (BMI centile) \\
\hline \multicolumn{2}{|l|}{ Medications } \\
\hline Statins & Group Lipid regulating drugs \\
\hline Antihypertensives & $\begin{array}{l}\text { Ace inhibitor, Angiotensin receptor antagonist, beta blocker, } \\
\text { thiazide, calcium channel blocker, alpha blocker, spironolactone, } \\
\text { aspirin }\end{array}$ \\
\hline \multicolumn{2}{|l|}{ Vascular comorbidities } \\
\hline Heart failure & G58.. Heart failure \\
\hline Hypertension & G2... Hypertensive disease \\
\hline
\end{tabular}

